\title{
Prevalence of respiratory symptoms in Parisian teenagers according to smoking habits
}

\author{
FRANCOISE NEUKIRCH, RENATA LIARD, JACQUELINE COOREMAN, SIMONE \\ PERDRIZET \\ From the Unité 179, INSERM, le Vésinet, France
}

SUMMARY The relationship between respiratory symptoms and smoking habits, according to sex, was studied in 2266 teenagers attending secondary school in Paris. Among smokers, the prevalence of usual cough or phlegm, or both, was higher in girls than in boys, whereas such was not the case among non-smokers. That prevalence, as well as the proportion of people with wheezing, were more closely associated with the total number of cigarettes ever smoked by girls than by boys. Moreover, there was a weak but significant association between the total number of cigarettes smoked and respiratory function- $\mathrm{FEV}_{1} / \mathrm{Ht}^{3}$ in girls only.

A study ${ }^{1}$ at an industrial medical centre in Paris showed that adult women were more vulnerable than men to the effects of smoking on respiratory symptoms. The object of the present study was to determine whether this was also the case among teenagers.

\section{Population and methods}

In October 1978 a large survey was carried out in a Paris State secondary school. Of the 2266 present on the day of the survey, all satisfactorily completed a self-administered questionnaire derived from the standard Medical Research Council questionnaire ${ }^{2}$ but adapted for teenagers. A random sample of 970 were then examined by measuring the forced expiratory volume in one second $\left(F E V_{1}\right)$ using a dry spirometer ( $\mathrm{TL}_{\mathrm{c}}$ Morgan).

The following definitions were used.

Smokers-An affirmative answer to the question "Do you usually smoke?" (at least one cigarette a day).

Total number of cigarettes ever smoked-The average number of cigarettes smoked daily multiplied by 365 , multiplied by the number of years smoking.

Usual cough or phlegm, or both-An affirmative answer to at least one of the following: usual morning cough, cough day or night, phlegm, chronic cough and phlegm on most days for three successive months for at least two years.
Wheezing-An affirmative answer to the question "does your chest ever sound wheezy or whistling when you are at rest?"

$F E V_{1} / H t^{3}-$ This variable has been used by Fletcher and others ${ }^{3}$ to standardise $\mathrm{FEV}_{1}$ for height.

\section{Results}

Of the 2266 pupils who completed the questionnaire $86 \%$ were French and $43 \%$ boys with a mean age of 14.9 years. Table 1 gives the age distribution by sex and by smoking habits. Of the boys $21.8 \%$ were current cigarette smokers as were $31 \cdot 2 \%$ of the girls; the mean age of male smokers was 16.5 years and of female smokers 16.4 years; the mean age of starting to smoke was $15 \cdot 2$ years for boys and $15 \cdot 1$ years for girls. Among the current smokers the proportion who were heavy smokers - that is, smoking more than 10 cigarettes a day-was $44.7 \%$ among boys and $42 \cdot 1 \%$ among girls. The only difference that achieved statistical significance of $p \leqslant 0.05$ was the proportion of current smokers that was higher among girls than boys.

Table 2 shows the numbers of respondents with usual cough or phlegm, or both, by sex and by smoking habits. The proportion was similar in non-smokers in both sexes, but among the current smokers $34.9 \%$ of the boys and $44.7 \%$ of the girls had cough or phlegm, or both.

The relation between the total number of cigarettes ever smoked and usual cough or phlegm, or 
Table 1 Age distribution by sex and smoking habits

\begin{tabular}{|c|c|c|c|c|c|c|c|c|}
\hline \multirow[b]{3}{*}{ Age (years) } & \multicolumn{4}{|c|}{ Boys } & \multicolumn{4}{|l|}{ Girls } \\
\hline & \multicolumn{2}{|c|}{ Non-smokers } & \multicolumn{2}{|c|}{ Smokers } & \multicolumn{2}{|c|}{ Non-smokers } & \multicolumn{2}{|c|}{ Smokers } \\
\hline & No & $\%$ & No & $\%$ & No & $\%$ & No & $\%$ \\
\hline $\begin{array}{l}\leqslant 11 \\
12-13 \\
14-15 \\
16-17 \\
\geqslant 18 \\
\text { Total }\end{array}$ & $\begin{array}{r}122 \\
216 \\
190 \\
144 \\
90 \\
762\end{array}$ & $\begin{array}{r}16.0 \\
28.4 \\
24.9 \\
18.9 \\
11.8 \\
100.0\end{array}$ & $\begin{array}{r}1 \\
12 \\
48 \\
95 \\
56 \\
212\end{array}$ & $\begin{array}{r}0.5 \\
5.7 \\
22.6 \\
44.8 \\
26.4 \\
100.0\end{array}$ & $\begin{array}{r}105 \\
222 \\
231 \\
244 \\
87 \\
889\end{array}$ & $\begin{array}{r}11.8 \\
25.0 \\
26.0 \\
27.4 \\
9.8 \\
100.0\end{array}$ & $\begin{array}{r}0 \\
6 \\
101 \\
208 \\
88 \\
403\end{array}$ & $\begin{array}{r}0.0 \\
1.5 \\
25.1 \\
51.6 \\
21.8 \\
100.0\end{array}$ \\
\hline
\end{tabular}

Table 2 Numbers and proportions of respondents with usual cough or phlegm, or both, by sex and smoking habits

\begin{tabular}{|c|c|c|c|c|c|}
\hline & \multicolumn{2}{|l|}{ Boys } & \multicolumn{2}{|c|}{ Girls } & \multirow{2}{*}{$\begin{array}{l}\text { Results } \\
\text { of } x^{2} \text { tests }\end{array}$} \\
\hline & No & $\%$ & No & $\%$ & \\
\hline $\begin{array}{l}\text { Non-smokers } \\
\text { Smokers }\end{array}$ & $\begin{array}{r}199 \\
74\end{array}$ & $\begin{array}{l}26 \cdot 1 \\
34.9\end{array}$ & $\begin{array}{l}239 \\
180\end{array}$ & $\begin{array}{l}26 \cdot 9 \\
44 \cdot 7\end{array}$ & $\begin{array}{l}\text { NS } \\
p<0.05\end{array}$ \\
\hline
\end{tabular}

both, and wheezing is shown for each sex in fig 1 . The girls had a higher proportion of affirmative responses to both symptoms at every level of cigarette smoking above a total of 4000 cigarettes ever smoked.

Figure 2 shows the correlation between total number of cigarettes ever smoked and $\mathrm{FEV} / \mathrm{Ht}^{3}$ for each sex. Among boys the correlation was $\mathrm{r}=+0.13, \mathrm{p}>0.05$; among girls $\mathrm{r}=-0.21$, $p=0.012$, thus there was a weak but significant association between total number of cigarettes smoked and a reduction in respiratory function in girls.

Other possible confounding factors such as age, previous tuberculosis or pleurisy, and parents' smoking habits, were studied, but none of them appeared to influence these results. In fact when tests were adjusted for these factors they gave the same degree of significance as the unadjusted tests.

No significant correlation between the prevalence of asthma and cigarette consumption was found in boys or girls.

\section{Discussion}

The results of this study show that the greater vulnerability of females to the effects of smoking on respiratory symptoms begins during adolescence.

In French adults ${ }^{1}$ the relative risk of having chronic respiratory symptoms if one smokes was greater in women than in men, but the absolute risk was similar in both sexes. The relative risk was greater in women because the prevalence of symptoms in female non-smokers was about one-half that of male non-smokers. A similar result has been found in Canada (J A Dosman, paper presented at Canadian Thoracic Society Annual Meeting 1977). In contrast,

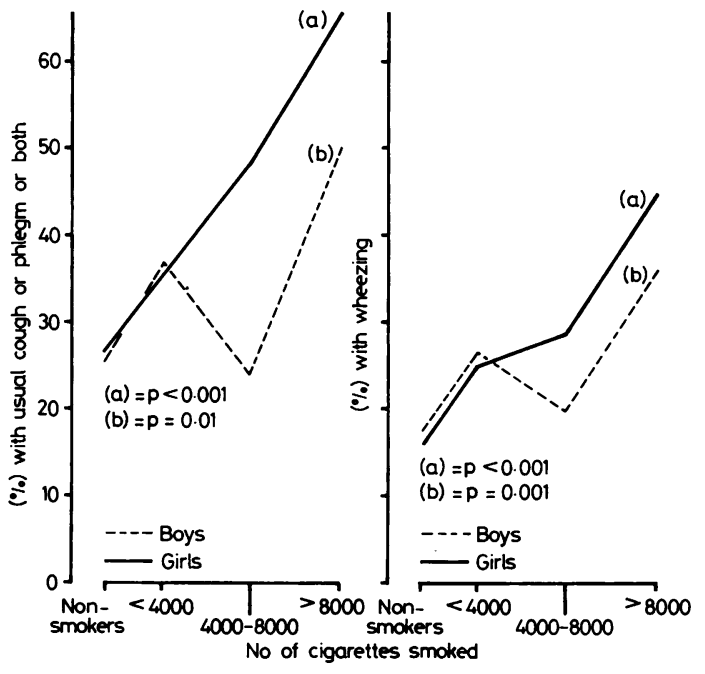

Fig 1 Frequency of subjects with respiratory symptoms according to the total number of cigarettes ever smoked, by sex.

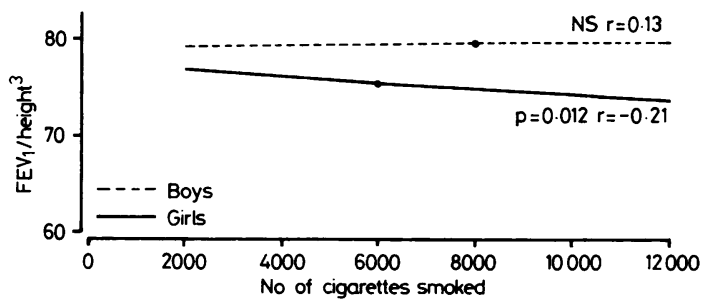

Fig 2 Regression of $\mathrm{FEV} / \mathrm{Ht}^{3}$ on the total number of cigarettes ever smoked, by sex.

in the present survey male and female non-smokers had the same prevalence of usual cough or phlegm, or both, but girls who smoked had a greater absolute risk. This might suggest that in people without any occupational hazards men are not more likely to have respiratory troubles than women, and also that the vulnerability of women to the effects of smoking is greater than previous studies in adults have suggested. 
None of the possible confounding factors that we have studied appeared to influence these results. Unfortunately, we were not allowed to ask questions about the social class of the parents, but we know that the district served by that State secondary school is neither underprivileged nor especially privileged and that the social level is fairly homogeneous, so we do not think this study is biased on that account.

A possible psychological bias must be considered: in fact one might argue that in population-based health surveys women report more illness than men, ${ }^{5}$ and even that women who smoke overestimate their ill health more than the others. We think that if it were true the answers to the question about asthma would follow the same pattern as the other answers, but no correlation between cigarette consumption and the prevalence of asthma was found despite the high correlation with wheezing. Moreover, spirometric results provided objective evidence and confirmed the existence of a problem in girls. These results were not very striking, but it would have been alarming to find a greater loss of pulmonary function in such young people who had smoked a few cigarettes. Dosman et al found that mean predicted values for $F E V_{1}$, forced vital capacity, and maximum mid-expiratory flow rate were significantly lower in the female smokers than the male smokers: these differences were largest in the 40-49 age cohort and increased when expressed as a function of pack years. Our results show that this process begins in adolescence.

Evidence on this subject is still inadequate, and no conclusion is drawn in the report of the United States Surgeon General. ${ }^{5}$ Few studies among those quoted in the directory On-going Research in Smoking and Health, ${ }^{6}$ deal with this problem. Still, with a view to public health policy, it is important to answer the question whether women are really more vulnerable than men to health hazards due to smoking.

This work was supported by the CRL No 7952955 of INSERM. Requests for reprints to: Mrs F. Neukirch, INSERM, U 179, 44 Chemin de Ronde, BP 34, 78110 le Vésinet, France.

\section{References}

${ }^{1}$ Liard R, Perdrizet S, Cooreman J, Bidou S. Smoking and chronic respiratory symptoms: prevalence in male and female smokers. Am J Public Health 1980; 70: 271-3.

${ }^{2}$ Medical Research Council, Committee on Research into Chronic Bronchitis (1966). Questionnaire on respiratory symptoms. London: MRC, 1966. (Instructions for the use of the questionnaire on respiratory symptoms-Dawlish, Devon: WJ Holman, 1966.)

${ }^{3}$ Fletcher C, Peto R, Tinker C, Speizer FE. The natural history of chronic bronchitis and emphysema. 1st ed.O London: Oxford University Press. 1970.

${ }^{4}$ Nathanson CA. Sex roles as variables in the interpretation of morbidity data: a methodological critique. Int $J \propto$ Epidemiol 1978; 7: 253-62.

${ }^{3}$ US Surgeon General. The health consequences of smoking for women. Rockville: US Department of Health and Human Services, 1980: 360.

- US Department of Health and Human Services, Office on Smoking and Health. 1980 Directory On-going research $\exists$ in smoking and health. Rockville: US Department of Health and Human Services, 1980: 440. 